\title{
REFLEXIONES DE JUAN CRUZ VARELA SOBRE LA TRADUCCIÓN DE LA ENEIDA
}

\author{
Luis Marcelo Martino \\ Universidad Nacional de Tucumán-CONICET (Argentina)
}

\section{Resumen}

La necesidad de contar con "una traducción [en español] que merezca leerse" — tales son sus palabras - impulsa a Juan Cruz Varela, representante por antonomasia del neoclasicismo argentino, a emprender hacia 1829 su propia versión de la Eneida de Virgilio. En 1836, Varela le escribe a Bernardino Rivadavia una extensa carta sobre la tarea que lleva a cabo. En el presente trabajo nos proponemos analizar las reflexiones de Varela en dicha carta sobre la traducción en general y, en particular, sobre la traducción de la Eneida, así como también su postura frente a algunas versiones en lengua romance de la epopeya.

Palabras clave: Eneida, Juan Cruz Varela, traducción, clasicismo, literatura argentina.

\section{JUAN CRUZ VARELA'S REFLECTIONS ON THE TRANSLATION OF THE AENEID}

\begin{abstract}
In 1829 Juan Cruz Varela, the most important figure of the Argentinian Neoclassicism, begins his translation of Virgil's the Aeneid stimulated by the need to have "a [Spanish] translation that is worth reading", in his own words. In 1836 Varela wrote a long letter to Bernardino Rivadavia on this matter. The purpose of our work is to analyse Varela's reflections on translation in a broad sense and, more particularly, Varela's ideas on the translation of the Aeneid and his attitude towards some French and Spanish versions of the epic poem.

Keywords: The Aeneid, Juan Cruz Varela, translation, classicism, Argentinian literature.
\end{abstract}


[...] cuando todas las naciones cultas tienen traducciones más o menos célebres de la Eneida, en sus respectivos idiomas [...] solo los españoles no tienen de aquel poema una traducción que merezca leerse.

Carta de J.C. Varela a J.M. Gutiérrez (7 de septiembre de 1838).

\section{Introducción}

En su Estudio sobre las obras y la persona del literato y publicista argentino D. Juan de la Cruz Varela, Juan María Gutiérrez (1809-1878) testimonia que hacia mediados de 1829, Varela (1794-1839), desterrado en Uruguay, comienza a traducir la Eneida (1871: 117). Esta tarea se interrumpe algunos años después, en 1835, por problemas de salud del poeta, según asegura el hermano de este, Florencio (1807-1848) en carta a Gutiérrez del 21 de agosto de ese año. No obstante, el proyecto se encontraría en estado avanzado y pronto volvería a ponerse en marcha, según palabras del propio Florencio (Mogliay García, 1979: 188), quien, el 29 de enero de 1836, en otra epístola a Gutiérrez, le informa que Juan Cruz ha concluido la traducción del primer libro de la Eneida, que ciertamente le sería enviado para su lectura (Moglia y García, 1979: 195).

Durante los primeros meses de 1836, entonces, Juan Cruz habría comenzado a difundir entre algunos parientes y amigos la traducción del canto primero de la epopeya. En una carta fechada el 29 de abril de ese año, el poeta le escribe desde su exilio en Hervidero (Uruguay) a su amigo, el ex-presidente argentino Bernardino Rivadavia (1780-1845), desterrado en la ciudad de Colonia ${ }^{1}$.

El texto, con el título de "Carta inédita de don Juan C. Varela al Sr. don Bernardino Rivadavia sobre la manera de traducir los poetas latinos y especialmente a Virgilio", es publicado por Gutiérrez en el número 11 de la Revista del Río de la Plata. Periódico semanal de historia y literatura de América (1872). En 1888, Adolfo Saldias transcribe la carta en un volumen que recoge las traducciones parciales de la Eneida al castellano realizadas por Varela y por el jurista Dalmacio Vélez Sarsfield (1800-1875) (Saldías, 1888: 319-337). Posteriormente, A. Farías Leal (1939: 137-160) reproduce en el apéndice de su libro El Arte de la Traducción Latina, bajo el encabezado "De nuestra literatura" (en referencia a la literatura argentina), la carta mencionada, a la que agrega "títulos adicionales" con el objeto de "facilitar su lectura".

La publicación completa del primer libro de la Eneida traducida por Varela se concreta recién en 1874, en el número 34 (tomo ix) de la Revista del Río

1 Para un estudio de las peripecias del proyecto de traducción de la Eneida de Varela, Martino (2014). 
de la Plata. En 1869 habían visto la luz en la Revista de Buenos Aires (año vii, n. $\left.{ }^{\circ} 75\right)$ los versos 1 al 185 del libro segundo (Pagés, 1961: 290-291; Guitarte, 1962: 258). Gutiérrez, por su parte, había transcrito en 1871 una selección de fragmentos destacados en su ensayo sobre Juan Cruz, acompañada de un análisis crítico. Una década más tarde, en 1883, Calixto Oyuela publica en el primer número de la Revista Científica y Literaria la traducción de los versos 1 al 273 del segundo canto (Pagés, 1961: 290; Guitarte, 1962: 258).

\section{De cómo imitar lo inimitable}

Yves Chevrel (1994: 165) llama la atención, en su artículo sobre los estudios de la recepción, sobre el "discurso de acompañamiento" de las versiones traducidas, destinado a facilitar la lectura de un texto extranjero y "señalar sus dificultades". Esta categoría podría emplearse - salvando las distancias - para caracterizar la carta de Varela a Rivadavia, donde este no solo se dedica a justificar sus decisiones como traductor y los obstáculos de su tarea, sino que hasta se permite poner en diálogo distintas traducciones.

La extensa carta resulta, en efecto, digna de atención, ya que en ella Juan Cruz se explaya sobre sus ideas generales acerca de la traducción y, fundamentalmente, sobre su propia tarea de volcar la Eneida al español. La muerte reciente de su hija Corina lo ha sumido en un estado de angustiay abatimiento. No obstante, consigue concentrarse y ordenar sus ideas, a instancias de Rivadavia, a quien agradece en la carta el haberle comprometido a hablar sobre la materia e incentivarlo a retomar la tarea de la traducción (Varela, 1872: 415).

Después de exponer las tristes circunstancias que atraviesa, Varela propone cambiar de tema: "Hablemos de otra cosa". Esa "otra cosa" será "mi traducción [de la Eneida], o, más propiamente hablando, [...] la idea que yo me he formado del modo cómo debe traducirse Virgilio" (405)².

La exposición de Varela arranca con una comparación del estilo de distintos autores latinos:

Desde luego, hay poetas latinos, cuyo texto más oscuro que el del Mantuano, y cuya dicción, por decirlo así, más complicada, parece que deberán embarazar más al traductor. Juvenal el primero, y Horacio mismo, entran en este número. Mas yo creo que la simplicidad majestuosa, la claridad sublime, el estilo de Virgilio, siempre elevado, pero siempre fácil, hacen más espinosa la traducción de sus obras. Supuesta la instrucción necesaria, bastan, para vencer las dificultades que presenta el texto de los otros, un conocimiento

${ }^{2}$ A partir de aquí citamos únicamente las páginas de la obra de Varela (1872). Hemos optado por modernizar la ortografia de todas las citas. 
perfecto del idioma latino, y el trabajo de confrontar las varias lecciones, y de consultar los mejores intérpretes. Pero no basta esto para traducir bien a Virgilio: el que vertiera sus versos con claridad, pero con prosaísmo; y el que dijera, en cualquiera de nuestras lenguas, lo mismo que el dijo en la suya, sin añadir ni quitar cosa alguna, pero que lo dijera en un estilo oscuro, en una poesía enigmática, y con frases complicadas, distarian igualmente de lo que es aquel modelo, y no darían de él una idea aproximada (405-406).

En este punto, podríamos decir, Varela habla con conocimiento de la materia. Si bien nolo dice en su carta, antes de ocuparse de la Eneida ya ha traducido a otros autores latinos. Entre los "primeros pasos de nuestro poeta en la carrera" de la traducción, según Gutiérrez, se cuenta una versión en octavas castellanas de la elegía tercera de las Tristia de Ovidio, a modo de "ensayos de colegial" (Gutiérrez, 1871: 102-103). Posteriormente, en 1832, el periódicouruguayo El Patriota publicaría algunas odas de Horacio que Varela "se había atrevido a traducir", según afirma Gutiérrez, citando las propias palabras del poeta ${ }^{3}$. No se trata, entonces, de un traductor primerizo. Por otra parte, ya se había aproximado a la epopeya virgiliana algunos años atrás. En 1823 había publicado una tragedia titulada Dido, basada en el episodio narrado en el libro iv de la Eneida (Gutiérrez, 1971: 50-51; 116-117).

La aventura en la que se ha embarcado Varela, según sus propias palabras, no es sencilla. Tomás de Iriarte ya había dejado constancia, en su edición de los cuatro primeros libros de la Eneida en versos castellanos, de "la suma dificultad que de suyo tiene la empresa aún para hombres de elevado ingenio" (Iriarte, 1805: xvii). Ya sobre el final de su carta, el poeta argentino volverá a afirmar que se trata de un "largo y penoso trabajo", "un trabajo que exige tranquilidad y mucho tesón", no apto, por lo tanto, para "un hombre habitualmente enfermo y aquejado de dolores" (415). Podemos sostener, sin intención de cuestionar o desmerecer la valoración de Varela sobre las dificultades de traducir la Eneida, que estas palabras están dirigidas a realzar la tarea que lleva a cabo y a configurar una imagen de sí mismo como traductor, que se enriquecerá con otros rasgos a lo largo de la carta, como veremos más adelante. Esta imagen se corresponde con la figura tradicional del traductor que Gaspar (2014:46) descubre en el cuadro de Caravaggio, San Jerónimo escribiendo: un traductor "abnegado y responsable, adicto en el sentido etimológico del término [...]. La tarea es un sacrificado y estudioso cotejar para ser fiel».

En concordancia con esta imagen, Gutiérrez (2006: 18), en un texto de 1846, caracteriza a Varela como un "infatigable atleta poético" que "traduce

\footnotetext{
${ }^{3}$ Gutiérrez (1871: 103). Las cursivas pertenecen al original.
} 
a Horacio y muere con la Eneida en la mano, esforzándose por continuar la versión de este poema". Los esfuerzos de Varela no se deben solo a las dificultades inherentes a la tarea de la traducción. A las dolorosas circunstancias familiares (el fallecimiento de su hija), se suma el hecho de que escribe lejos de su patria. Fontana (2015: 159) identifica, en el estudio que Gutiérrez le dedica a Juan Cruz, "una imagen biográfica muy atractiva: el exiliado que traduce». Esta imagen se hace presente en los tramos finales de la carta, cuando Varela (1872: 416) expresa su anhelo de que su Eneida se publique en su patria.

Para completar la idea de las dificultades que entraña traducir a Virgilio, Varela presenta una serie de traductores anónimos, potenciales — -el que vertiera sus versos...", "el que dijera, en cualquiera de nuestras lenguas..."que no arribarian a una versión convincente. Dichos traductores cobrarán vida y adquirirán nombre y entidad con el correr de la exposición.

A continuación, Varela ofrece una fórmula sintética para traducir a Virgilio:

Así que, yo pienso que lo que debe sobre todo procurarse traduciendo al Mantuano, es imitar su estilo y conservar sus bellos colores; y esto precisamente es lo que desespera al que pretende traducirle. Un verso, por sonoro y elevado que sea, si no tiene la fluidez, la elegancia y la melodia que distinguen a los de Virgilio, no se parecerá jamás a ellos (406).

La figura del traductor sin nombre vuelve a hacerse presente, esta vez sumido en la desesperación, abandonando un proyecto que no pasaría de ser solo una pretensión. Por contraste, los méritos de aquel que no ha desistido de la empresa y que, sobre todo, ha arribado a buen puerto - es decir, Varela- brillan con más esplendor. Sobre todo, si este traductor es capaz de reflexionar a conciencia sobre su tarea y ofrecer, fruto de aquella reflexión, consejos y máximas pronunciadas en tono didáctico y magistral: "lo que debe sobre todo procurarse..." ${ }^{4}$.

Asoma en las palabras de Varela una concepción de la traducción como imitación de un estilo, que intenta reproducir en la lengua destino las cualidades y rasgos estilísticos deloriginal. El propio Varela, como veremos, se encargará de aclarar el alcance y sentido en que emplea el término "imitación".

Una vez establecidos cuáles son los requisitos necesarios para traducir bien a Virgilio, Varela se consagrará a evaluar distintas versiones de la Eneida, incluida la suya propia. El movimiento argumentativo de la carta consiste en la exposición de ideas y conceptos generales sobre cómo debe ser una

4 El énfasis es nuestro. 
buena traducción de Virgilio y la presentación de ejemplos particulares, a modo de pruebas del cumplimiento o desvío respecto de dichos conceptos.

La primera versión de la Eneida que juzga Varela es una que solo existe en el plano de los anhelos:

Esto es lo que yo creo que no han comprendido bien los traductores de que yo tengo conocimiento; y esto es lo que me ha hecho siempre sentir, como quizá lo he significado a usted alguna vez, que Virgilio no haya sido traducido por Racine. En cuanto yo conozco en poesía, nada encuentro más parecido a los versos del épico latino que los del trágico francés, a pesar de ser tan diverso uno y otro género (406).

Aquellos traductores anónimos y potenciales de Virgilio a los que se refería Varela de manera general comienzan ahora a materializarse. El reproche - el desconocimiento del hecho de que una traducción que no respete la fluidez, elegancia y melodía virgiliana será fallida - apunta en este caso a "los traductores de que yo tengo conocimiento". El poeta, por el momento, no los identifica por sus nombres. El carácter general de la afirmación hace suponer que la descalificación los alcanzaría, en principio, a todos. Quedaría exceptuado Jean Racine, quien nunca tradujo la Eneida. Varela, como vemos, evalúa una traducción virtual, ideal, inexistente de hecho. Su especulación de que una versión de la epopeya realizada por Racine habría sido satisfactoria se basa en el conocimiento que tiene de la obra poética del autor francés. En el fondo, yace la idea de que un buen poeta será necesariamente un buen traductor de poesía, idea que contaba en ese momento con una ilustre tradición. Ya en el siglo xvii, John Dryden, siguiendo a George Chapman — traductor de la Ilíada (1611) y la Odisea (1614)—, había establecido como norma que "el traductor de poesía debe ser poeta y congeniar con el autor, amén de poseer unos conocimientos lingüísticos extraordinarios" (Vega Cernuda, 1996-1997: 78).

Tras manifestar su deseo de que existiera una Eneida de Racine, Varela vuelve la mirada hacia su propia versión:

¿Habré conseguido, no digo ya imitar, pero dar siquiera una idea en mis pobres versos de lo que son en sí mismos los de mi inimitable modelo? ¿Habré remedado de algún modo lo que usted llama, tan propiamente, el canto de Virgilio? Esto es, mi caro amigo, de lo que desconfio mucho; pero esto es lo que he procurado sobre todo, y lo que procuraré en adelante (406-407) 5 .

La constatación de la inimitabilidad de Virgilio no lo lleva a desistir de su tarea, aunque sílo obliga a moderar sus aspiraciones. Las preguntas de este

\footnotetext{
${ }^{5}$ Las cursivas pertenecen al original.
} 
pasaje constituyen un juego retórico en torno al manido tópico de la falsa modestia, que ofrece abundantes ejemplos a lo largo de la historia de la literatura y de la traducción. Como muestra, basta mencionar un par de casos, ambos circunscriptos a la traducción de la Eneida.

En el prólogo a su edición parcial de la epopeya, Iriarte desaconseja a quienes saben latín la lectura de la Eneida traducida: "A cualquiera que se halle en estado de leer y entender con fruto la Eneida en su original, no aconsejaré la estudie en Traducción alguna, y menos en la mía" (Iriarte, 1805: ix-x). Más adelante, se atribuye la responsabilidad por los posibles defectos de su versión, disipando con honestidad probables atenuantes y excusas: "Si el éxito no corresponde a mis anhelos, no pretendo se atribuya enteramente a la inferioridad de nuestra lengua respecto de la Latina, sino en gran parte a la inferioridad de mi talento respecto del de Virgilio" (Iriarte, 1805: xvii) $^{6}$.

Varios años después, Arrue (1845: 2), en el prólogo a su edición bilingüe de la Eneida, presentará su traducción como una obra imperfecta: "si logro despertar a los grandes ingenios que encierra la Nación, para acabar con más perfección lo que yo he emprendido para estimularlos [...] mi ambición queda satisfecha".

\section{Las traducciones francesas}

Una de las máximas que formula Varela sobre la traducción de los textos antiguos es que "no debe perderse de vista un momento que no son modernos" (407). "Muchos traductores de Virgilio", afirma, pasan por alto esta observación. Varela se detiene en un caso concreto: la traducción de la Eneida al francés realizada por Jacques Delille ${ }^{7}$ :

En una obra como la de Delille, tan recomendable bajo muchos respectos, se advierte a cada paso con sentimiento que están completamente alteradas las formas antiguas, y vertidos a la moderna, sí es lícito expresarse así no solo el poeta que celebró a los héroes de la Eneida, sino los mismos héroes celebrados (407).

Para fundamentar su juicio, Varela transcribe unos versos en latín del canto primero de la Eneida (vv. 617-618), acompañados de las correspon-

\footnotetext{
${ }^{6}$ Con respecto a este pasaje, Salas Salgado (2012:3) afirma que Iriarte "Se adelanta a las posibles críticas aduciendo (no deja de ser ello una variante del "tópico de la falsa modestia”) que los problemas que pudiera tener su versión no vienen de la inferioridad de la lengua castellana, sino de la suya propia".

${ }^{7}$ L'Énéide, traduite en vers français par Jacques Delille, avec des remarques sur les principales beautés du texte (París, Giguet et Michaud, 1804). Existe otra edición: L'Énéide, traduites [sic] en vers français par Jacques Delille. Avec les variantes, notes et imitations (Bruselas, Impr. J. Maubach, 1817).
} 
dientes versiones en español y en francés, la primera de su propia cosecha, la segunda perteneciente a Delille (407-408). Con esta confrontación, Varela se propone dejar en evidencia que el traductor francés adultera el discurso de la Eneida:

Dígame usted: aquel cumplimiento tan francés, pardonnez ma franchise, ¿podía ocurrir a Dido, ni a nadie en su tiempo? ¿No cree usted que esto choca con la idea que tenemos de las costumbres y usos de aquellos siglos y en lo que ellas eran verdaderamente? Por eso es que ni cosa parecida se encuentra en el original $(408)^{8}$.

Por su parte, su propia traducción, según afirma Varela con un dejo de falsa modestia, no incurriria en el vicio de Delille:

Yo he traducido:

$¿$ Conque eres el Eneas afamado,

Que a la margen del Frigio Simöente

Por el Dardanio Anquises engendrado,

Nació del alma Venus?

Esta versión tendrá todos los defectos que usted quiera pero me parece que no podrá reprochársele el que actualmente vitupero (407-408).

El "defecto" en cuestión constituye en realidad una deliberada opción de traducción. Guglielmi (2002: 302), al analizar la idea de infidelidad de una traducción, sostiene que este concepto "se relaciona con una interpretación del texto que no tiene en cuenta la realidad histórica, cultural y lingüística de la que proviene la obra, sino que la proyecta directamente en la cultura de llegada". La versión de Delille podría vincularse con elllamado fenómeno de las traducciones "bellas e infieles", que alcanza su apogeo entre los siglos xvii y xviii en Francia, sobre todo durante el reinado de Luis XIV, cuando se consideraba que los elementos foráneos debían ser modernizados (o sea, afrancesados) (Guglielmi, 2002: 302).

Núñez (2003: 151), siguiendo a Brooks Bartlett, afirma a su vez que Chapman dota "a sus traducciones de "la libre gracia del dialecto natural en que traducía”, y al efecto se valía de figuras y juegos de palabras para adornar su versión, usando un lenguaje coloquial y utilizando palabras que eran anacronismos con respecto a Homero".

Estos anacronismos son, precisamente, el objeto de la condena de Varela, quien concluye el análisis del pasaje de Delille con una rotunda declaración de principios: "Insisto, pues, en que es necesario, al traducir los autores de otras edades, que el traductor en lo posible, se haga su contemporáneo, y

${ }^{8}$ Las cursivas pertenecen al original. 
contemporáneo también de los personajes que esos autores presentan en la escena" (408).

Este reclamo de Varela podría asimilarse a una de las estrategias de traducción propuestas en 1813 por Schleiermacher (1996: 137), consistente en hacer que el lector se acerque al escritor, dejando a este "lo más tranquilo posible». Debemos aclarar, por una parte, que Varela no tiene presente al lector en su ecuación. Por otra parte, el poeta argentino nunca menciona en su carta de modo explícito ninguna reflexión ni teorización sobre la traducción, anterior o contemporánea a él, como por ejemplo las de los grandes referentes del momento (Chapman, Dryden y Schleiermacher). Naturalmente, esta ausencia no significa que no haya conocido dichas reflexiones.

Las críticas que Varela dirige a Delille no implican que no valore su trabajo, o algunos de sus aspectos. El solo hecho de que haya considerado su versión de la Eneida como ejemplo ilustrativo de sus afirmaciones y juicios resulta significativo de que le merece cierta consideración, a diferencia de otras versiones: "No quiero hablar de las traducciones castellanas de la Eneida, porque ellas apenas merecen ser citadas; y me contraigo a Delille, porque su trabajo es, con mucha razón estimado" (408). Varela menosprecia las traducciones españolas del poema virgiliano y decide, por eso mismo, excluirlas de su exposición. No obstante, esta exclusión no será absoluta, como veremos más adelante.

En otro pasaje de su carta, Varela expresa de manera más explícita la estimación que le merece la obra de Delille, para que no quede lugar a dudas:

Pero no vaya usted a creer, amigo mío, por estas observaciones, que yo trato de deprimir a un traductor a quien tanto debo, ni de compararme con él. Conozco sus dotes poéticas y su gran superioridad respecto de mí (415).

A pesar de este reconocimiento, teñido de falsa modestia, las comparaciones que plantea Varela en su carta entre la versión de Delille y la suya propia son tan explícitas, como vimos, que no resulta creíble su afirmación de que no pretende equipararse al francés.

Tras ocuparse de Delille, Varela trae a colación otra versión francesa de la Eneida, la de Auguste-Marseille Barthélemy9:

Deseo ver la traducción de Barthelemi [sic]: el carácter de este escritor que me es conocido por muchas obras suyas, responde seguramente que no incurrirá en el defecto de que trato ahora; pero temo mucho que bajo de otros respectos, quede inferior a Delille (408).

${ }^{9}$ L'Énéide, traduite en vers français par Barthélemy, avec le texte latin en regarde, précédé d'une préface, et accompagné de notes du traducteur (Liv. 1,2,3) (París, Perrotin-H. Fournier aîné, 1835). 
El defecto en el que "no incurrirá" Barthélemy es la inclusión de anacronismos, que, como vimos, Varela había criticado en Delille. Es interesante el empleo del verbo en tiempo futuro por parte del poeta argentino. La traducción de Barthélemy ya ha sido publicada, pero Varela no ha tenido acceso directo al texto. Como lo explicitará más adelante, solo ha tenido noticias de esta versión a través de "un largo artículo" de la prensa francesa que había leído en Montevideo y que posteriormente le remitió Rivadavia (416) ${ }^{10}$. Esta circunstancia no constituye, sin embargo, un obstáculo para que emita su juicio, que se basa, además de en la lectura del artículo mencionado, en el conocimiento que tiene del resto de la producción de Barthélemy: "Repito que no le conozco sino por sus obras: ellas me habrán hecho formar este concepto, quela lectura de su traducción me hará tal vezvariar» (408-409). En esta afirmación se percibe, nuevamente, la creencia en la vinculación estrecha entre la escritura poética en la propia lengua y la tarea de traducción de poesía.

Varela anhela conseguir la versión de Barthélemy con la misma intensidad con que se lamentaba de que Racine no hubiera traducido la Eneida. En una sofisticada operación de confrontación, el poeta argentino pone en diálogo tres versiones francesas de la epopeya latina: «El alma de Delille me parece más simpática con la de Virgilio [que la de Barthélemy]: la de Racine lo era más" (409). No solo especula sobre los méritos y defectos de una obra que no conoce, sino que se permite compararla con otras en la misma lengua: una que sí ha leído y otra que nunca fue escrita.

La confrontación que propone Varela entre distintas versiones de la Eneida constituye un testimonio de esas "complejas interacciones que se producen entre una traducción nueva y las que la han precedido" (Steiner, 2001: 134-135). En ese juego dinámico, Juan Cruz establece una suerte de competencia - de la que siempre saldrá victorioso- con otros traductores de la epopeya virgiliana, incluso con aquellos que traducen a un idioma que no es el español.

Más adelante, Varela recurrirá nuevamente a Delille. Tras concluir su disertación sobre las dificultades de respetar el número de versos del original en una traducción al español —cuestión de la que nos ocuparemos más adelante-, el poeta argentino reitera una afirmación, que podría considerarse su lema como traductor:

Porlo demás, mi sistema de traducir a Virgilio no es otro que eldeimitar enlo posible su estilo, yusar aun sus mismas palabras, en cuantolo permitan

\footnotetext{
${ }^{10}$ Bayard (2008: 49) señala que una de las formas más frecuentes de acceso a los libros y de "hacerse una idea bastante precisa de lo que un libro contiene sin necesidad de leerlo" consiste en «leer o escuchar lo que los demás escriben o dicen a su respecto".
} 
la lengua y las inmensas trabas, que cuando se traduce, presenta la versificación. Digo en cuanto lo permitan, porque usted sabe bien que una traducción, exacta en todo el rigor de la palabra, y de todo punto fiel y textual, es una obra de suyo imposible [...]. A cada paso se encuentra usted con la imposibilidad material de volver palabra por palabra; y, cuando esto sucede, lo que creo que debe hacerse es presentar el verdadero concepto del original, el pensamiento recto del autor, sin salir por ningún motivo de su idea, y empleando formas parecidas a las suyas, aunque no sean ellas mismas (412).

En este pasaje, Varela especifica a qué se refiere concretamente con su máxima de la imitación del estilo virgiliano, explicitando los factores que restringen su alcance: la gramática de la lengua de destino y las normas métricas imponen límites que no pueden obviarse. La fidelidad absoluta, por lo tanto, es un ideal inalcanzable. Coincidimos en este punto con González Delgado (2013: 461) cuando afirma, al analizar la declaración de Varela citada más arriba, que "no deben extrañarnos improvisaciones y algunas infidelidades [en su traducción de la Eneida]».

En este pronunciamiento contra la traducción literal se perciben ecos de las reflexiones de distintos traductores sobre su práctica, reflexiones a las que Varela no se refiere explícitamente. En primer lugar, podemos mencionar los principios sistematizados por Étienne Dolet en La manera de traducir bien de una lengua a otra (1540), concretamente el tercero: "[...] al traducir, no hay que someterse al texto hasta el extremo de traducir palabra por palabra "11 (López Carrillo et al., 1995: 127; Aranda, 2016: 14-15). Chapman (1865: 1xxviii-1xxix), por su parte, en su poema titulado "To the reader", que precede a su traducción de la Ilíada, sostiene la imposibilidad de la traducción word for word.

La postura de Varela frente a la traducción, podríamos sostener, resulta compleja y plena de matices. Alli reside su originalidad y la necesidad de su abordaje y estudio. Al no citar ninguna reflexión de poetas o traductores sobre su oficio o arte, Varela se siente en libertad de teorizar, tomando su propia práctica como punto de partida y combinando, a nuestro entender, distintas ideas y postulados que, suponemos, conocía. Su actitud frente a la traducción literal resulta paradigmática en este sentido. Si bien se pronuncia decididamente por el respeto del sentido de la obra original —elverdadero concepto del original» - y afirma la imposibilidad de "una traducción exacta en todo el rigor de la palabra, y de todo punto fiel y textual", su posicionamiento en contra de una traducción literal no es radical. En efecto, su sistema de traducción, como él mismo lo explicita, consiste en la imitación del estilo del autor "en lo posible", usando "aun sus mismas palabras, en

\footnotetext{
${ }^{11}$ La traducción pertenece a López Carrillo et al. (1995).
} 
cuanto lo permitan" la gramática y la métrica. En este margen de posibilidad y probabilidad que deja abierto, se desvela que Varela solo renuncia con desgano a una traducción ceñida a la letra del original.

\section{Las traducciones castellanas}

Otra cuestión que interesa de manera particular a Varela es la diferencia entre el número de versos de la obra original y el de la versión traducida:

Ahora diré a usted algo sobre el mérito de la concisión en las traducciones y sobre el número de versos de la mía. Desde luego, la precisión es un gran mérito en toda clase de escritos, y debe aspirarse a ella con empeño; pero yo no creo que para juzgar si una traducción de versos hexámetros latinos en endecasílabos castellanos carece o no de aquel requisito, sea buena regla contar el número de versos del original y la versión (409).

La extensión que Varela consagra a este punto - tres páginas de la carta- es comprensible, si consideramos que la finalidad que persigue es justificar el hecho de que su versión de la Eneida tenga más versos que el original: "contrayéndonos directamente a nuestro caso, es justo confesar que una traducción del latín al castellano es absolutamente imposible que tenga la misma extensión que el original" (409).

De este modo, pretende anticiparse a las críticas sobre este punto que pudieran surgir. Para ello, despliega una serie de argumentos basados en la diferente naturaleza de cada lengua, en el "genio y artificio de uno y otro idioma" (409). Para fundamentar la extensión de su traducción, aduce razones gramaticales - la ausencia de artículos en latín; "el privilegio" de esta lengua "de omitir palabras y a veces frases enteras" (409), entre otros rasgos-y métricas -el número de sílabas que puede contener un hexámetro excede al del endecasílabo (410-411) - . En este punto, recurre como autoridad a la versión de la Eneida realizada por Iriarte, una de las dos traducciones al español que mencionará en su carta: "Iriarte, en el primer libro de su Eneida, ha hecho, con corta diferencia el mismo número de versos que yo" (411).

La referencia a una traducción castellana - a pesar de que Varela se había propuesto no hablar de ellas - resulta prácticamente obligada, ya que el poeta argentino debe citar una versión en su propia lengua para probar su punto de vista. En este caso, las versiones francesas no le resultan útiles, dada las diferencias entre ambas lenguas romances, como él mismo se encarga de aclarar (411).

El empleo interesado de Iriarte queda en evidencia. Varela solo le reconocerá méritos en tanto sirva para validar su propia traducción, es decir, en tanto funcione como argumento autojustificatorio. Es precisamente esta situación la que se encuadraría dentro del margen que dejaba el "apenas" 
en su afirmación anterior de que las traducciones castellanas "apenas merecen ser citadas" (408). Y ese contexto es el que explica el elogio que Varela hace de Iriarte: "y la traducción de Iriarte mirándola solo por lo textual y ceñida a la letra, puede llamarse perfecta" (411). A continuación, y como para que no queden dudas de que la perfección no existe, al menos en las obras ajenas, y de que su menosprecio de las traducciones españolas permanece incólume, Varela relativiza dicho elogio: "en lo demás [la traducción de Iriarte] no se parece a Virgilio" (411).

A modo de conclusión de su exposición sobre la concisión, Varela arriesga una opinión, que bien podría considerarse una máxima:

En resultado de todo, y de mis propias observaciones, creo que la precisión en traducciones de esta clase consistirá, no en hacer tantos versos cuantos tenga el original, o muy aproximadamente, sino en decir solo aquello que el original diga, y del modo y en la forma más parecida a él, cuanto lo permita la lengua (411).

Esta afirmación de la fidelidad al original, regida por la naturaleza de la lengua destino, remite a aquella crítica a la alteración de las "formas antiguas" en que habría incurrido Delille mediante la inclusión de expresiones anacrónicas. Solo que en este caso Varela se refiere a cuestiones formales, cuantitativas, para lo cual vuelve a convocar a los franceses:

Yo temo que el prurito de hacer menos versos que Delille, y de aproximarse al número material de los de Virgilio, prurito que hasta cierto punto, me parece pueril, ha de contribuir a que la traducción de Barthelemi [sic] no sea tan clara, tan elegante, tan suelta, como deben serlo todas las de Virgilio; y a que abunde en versos atormentados y duros (411).

Delille y Barthélemy vuelven a salir a la liza y, una vez más, el primero resulta victorioso. Pero en esta ocasión, Varela hace ingresar a la palestra a otro contendiente, quien ya ha sido derrotado de antemano: "No crea usted por esto que apruebo la redundancia de Velazco [sic]: todo extremo es vituperable; $y$, en cuanto sea posible, toda traducción debe ser ceñida" (411-412). Esta segunda referencia a una traducción española es aún más escueta y circunstancial y, a diferencia de la anterior, no contiene ningún elogio, ni siquiera uno parcial. El traductor en cuestión es Gregorio Hernández de Velasco, responsable de una versión de la Eneida publicada a mediados del siglo xvi, y objeto de numerosas reediciones ${ }^{12}$.

\footnotetext{
${ }^{12}$ Mayáns y Siscar (1795: 74-78) anota en su Vida de Virgilio (publicada en 1778 y reeditada de manera póstuma casi 20 años después) que la traducción de Hernández de Velasco tenía hasta ese momento tres impresiones: la primera en 1557, la segunda sin indicación de fecha y la tercera de 1586.
} 
Resulta evidente la desproporción entre el análisis que Varela dedica a la versión de Delille y la escasa atención que brinda a las versiones castellanas. Creemos que, de haber tenido a mano la traducción de Barthélemy y de haber existido la de Racine, las habría citado profusamente, aunque no necesariamente (o exclusivamente) para elogiarlas. Con respecto a las versiones castellanas que menciona en su carta, Varela no transcribe ni una sola línea, ni siquiera con espíritu destructivo.

Esta actitud de relativa indiferencia revela, a nuestro entender, un intento por dotar de originalidad a su trabajo ante los ojos de Rivadavia. Las citas de otras versiones al castellano - es decir, la lengua a la que él mismo traducepodrían producir un efecto contraproducente: opacar su propia traducción. La descalificación de las versiones anteriores en su lengua contribuye además a configurar una imagen del traductor pionero, un tópico también presente —valga la ironía - en el prólogo de la traducción de Hernández de Velasco (1768:vi-vii), a cargo del impresor, quien afirma que aquel pretendió "hacer principio y abrir camino a los que en este género de ejercicio quisieren en Virgilio hacer prueba de sus ingenios".

Por otra parte, podría leerse en esta actitud de Varela un gesto de reafirmación de la cultura nacional y de distanciamiento de la ex-metrópoli colonial. En una carta a Gutiérrez de 1838, citada en el epígrafe de este trabajo, Varela afirmará que los españoles son los únicos que "no tienen de aquel poema [la Eneida] una traducción que merezca leerse" (Gutiérrez, 1871: 119). Dado que España era el proveedor histórico de traducciones de los clásicos, la afirmación dejaría en evidencia un vacío, una carencia en el caso de la epopeya virgiliana. Una carencia que, como demuestra González Delgado (2013: 459) en su artículo sobre la recepción de la literatura grecolatina en Iberoamérica, no era absoluta, dado que ya existian versiones iberoamericanas de la Eneida, tales como la del mexicano José Rafael Larrañaga - que comienza a publicar su traducción de la obra completa de Virgilio en 1787-y una traducción colombiana, parcial (libros i-iv) y anónima, datada a fines del siglo xviii o principios del xix.

El menosprecio de las traducciones producidas en España obedecería, entonces, a razones ideológicas y podría leerse como una afirmación sobre la necesidad de que la nueva nación —independizada políticamente apenas un par de décadas atrás- cuente con sus propias traducciones de los clásicos grecolatinos ${ }^{13}$.

${ }^{13} \mathrm{Al}$ respecto, Fontana (2015: 161) afirma que Gutiérrez, en su estudio sobre la vida y obra de Varela, "advierte en el proyecto de traducción de Varela [una efectividad] [...] de política literaria, porque Varela [...] elige textos necesarios; textos que -como la Eneida o la Comedia - una cultura joven como la argentina estaba en la necesidad de incorporar". 
En junio de 1837, en la librería de Marcos Sastre, en Buenos Aires, se instaura el llamado Salón Literario. En una de sus reuniones, Sastre pronuncia un discurso en el que alude a la traducción en curso de Varela: "Sabemos que se desempeña admirablemente por otro poeta argentino una versión de la Eneida, que llevará mucha ventaja a las traducciones españolas de este poema" (Weinberg, 1977: 132). No menciona al responsable de la traducción, pero indudablemente remite a Juan Cruz. La alusión resulta significativa, ya que se inserta en un discurso que pretende trazar un panorama de la literatura argentina de la época. La traducción de Varela se pone así en relación con obras consideradas fundadoras de la literatura nacional, tales como el poema "La Cautiva" de Esteban Echeverría, el vate romántico argentino por antonomasia (Weinberg, 1977: 132).

En el mismo Salón, Gutiérrez se refiere en su discurso a la necesidad de concretar la independencia cultural:

Quedamos aún ligados por el vínculo fuerte y estrecho del idioma; pero este debe aflojarse de día en día, a medida que vayamos entrando en el movimiento intelectual de los pueblos adelantados de la Europa. Para esto es necesario que nos familiaricemos con los idiomas extranjeros, y hagamos constante estudio de aclimatar al nuestro cuanto en aquellos se produzca de bueno, interesante y bello (Weinberg, 1977, 153-154).

Las traducciones representan, para Gutiérrez, un medio por el cual aclimatar los productos culturales foráneos e incorporarlos al acervo cultural local. Gutiérrez vuelve a aludir a la figura del "traductor aclimatador" —analizada por Gaspar (2014: 54-59) — en una reseña de las traducciones virgilianas de Miguel Antonio Caro (1873) y Fermín de la Puente y Apezechea (1874), publicada originalmente en la Revista del Río de la Plata el $1 .^{\circ}$ de febrero de 1875. Allí Gutiérrez (1890: viii) se refiere a "la aptitud de los literatos sudamericanos para aclimatar en el terreno de las lenguas vivas [...] los sentimientos de los poetas de la antigüedad clásica». Esta revalorización de la capacidad de los "literatos sudamericanos" coincide con aquel desprecio de Varela por las traducciones de la Eneida realizadas en la Península, que contribuiría a posicionarlo como literato apto para realizar la necesaria aclimatación del patrimonio grecolatino.

\section{Consideraciones finales}

Jorge Luis Borges afirma que "cada escritor crea a sus precursores» ${ }^{14}$. De modo semejante, $\mathrm{y}$ haciendo uso de una paráfrasis plena de licencias, podríamos afirmar que cada traductor hace lo propio. Varela traza en su

${ }^{14}$ Borges (2011: 95). La cursiva pertenece al original. 
carta una genealogía incompleta de traductores de la Eneida, sesgada, de la que ilumina u oculta zonas - y personajes-en función de sus intereses. Propone en consecuencia una tradición en la cual insertarse y con respecto a la cual concordar o desviarse.

Varela no parece tener escrúpulos a la hora de desmenuzar algunas de las versiones de traductores anteriores, señalando errores y aciertos. Contrasta en este sentido con la cautela de Iriarte, quien se limita en su prólogo a mencionar aquellas traducciones que ha examinado cuidadosamente, absteniéndose de realizar observaciones criticas (Iriarte, 1805: xxi). Una explicación de la diferencia de actitudes residiría, a nuestro entender, en la naturaleza de cada texto. Mientras que Iriarte expone - o se excusa de exponer- sus opiniones y juicios en un prólogo que se publica junto a su versión de la Eneida, Varela se explaya con la libertad y confianza que le garantiza el género de la carta íntima, dirigida a un amigo.

\section{Bibliografia}

Aranda, L.V. (2016): Introducción a los estudios de traducción. Maryland, University Press of America.

Arrue, A. de (1845): Nueva versión de la Eneida de Virgilio en verso español acompañada del texto latino al frente, el más correcto. Bilbao, Impr. Adolfo Depont, tomo i.

Bayard, P. (2008): Cómo hablar de los libros que no se han leído. Barcelona, Anagrama.

Borges, J.L. (2011): «Kafka y sus precursores». En Borges, J.L.: Obras completas. ii: Otras inquisiciones. Buenos Aires, Sudamericana, págs. 93-95.

Chapman, G. (1865): "To the reader». En Chapman, G.: The Iliads of Homer, prince of poets. Done according to the Greek by George Chapman. Londres, John Russell Smith, vol. i, págs. lxxv-lxxxiii.

Chevrel, Y. (1994): «Los estudios de recepción”. En Brunel, P.y Chevrel, Y. (dirs.): Compendio de literatura comparada. México, Siglo XXI, págs. 148-187.

Farias Leal, A. (1939): El Arte de la Traducción Latina. Buenos Aires, San José.

Fontana, P. (2015): «Juan María Gutiérrezy la traducción. Los casos de José Antonio Miralla y Juan Cruz Varela». Quaderns. Revista de Traducció, 22, págs. 149-166.

Gaspar, M. (2014): La condición traductora. Sobre los nuevos protagonistas de la literatura latinoamericana. Rosario, Beatriz Viterbo.

González Delgado, R. (2013): "Literatura grecolatina e Iberoamérica». En García Jurado, F. et al. (eds.): La historia de la Literatura Grecolatina en España: de la Ilustración al Liberalismo (1778-1850). Analecta Malacitana, anejo 90. Málaga, Universidad de Málaga, págs. 443-467.

Guglielmi, M. (2002): «La traducción literaria». En Gnisci, A. (ed.): Introducción a la literatura comparada. Barcelona, Crítica, págs. 291-345.

Guitarte, G.L. (1962): «Cartas desconocidas de Miguel Antonio Caro, Juan Maria Gutiérrezy Ezequiel Uricoechea». Boletín del Instituto Caro y Cuervo, xvii, págs. 237-312. 
Gutiérrez, J.M. (1871): Estudio sobre las obras y la persona del literato y publicista argentino D. Juan de la Cruz Varela. Buenos Aires, Imprenta y Librería de Mayo.

- (1890): "Virgilio en América». En Caro, M.A.: Eneida por Publio Virgilio Marón. Traducción en versos castellanos por Miguel Antonio Caro. Madrid, Impr. Viuda de Hernando y Cía., tomo i, págs. vii-xxvii.

- (2006): «Prólogo de la primera edición de la América Poética». En Gutiérrez, J.M. y Gómez García, J.G. (sel.): De la poesía y elocuencia de las tribus de América y otros textos. Caracas, Ayacucho, págs. 15-20.

Hernández de Velasco, G. (1768): La Eneida de Virgilio, traducida en verso castellano. Madrid, Impr. Francisco Xavier García, tomo i.

Iriarte, T. de (1805): Colección de obras en verso y prosa. Tomo iii. Que contiene los quatro primeros Libros de la Eneida de Virgilio, traducidos en verso castellano. Madrid, Impr. Real.

López Carrillo, R. et al. (1995): «Étienne Dolet o los cinco principios de la traducción». En Lafarga, F. et al. (eds.): La Traducción. Metodología / Historia / Literatura. Ámbito hispanofrancés. Barcelona, ppu, págs. 123-130.

Martino, L.M. (2014): "Traduciendoal héroe. Eneas en elRíodela Plata».Praesentia. Revista venezolana de estudios clásicos, 15, págs. 1-19.

Mayáns y Siscar, G. (1795): Vida de Publio Virgilio Marón, con la noticia de sus obras traducidas en castellano. 2. ${ }^{\text {a }}$ edición. Valencia, Of. Hermanos de Orga.

Moglia, R.J. y García, M.O. (eds.) (1979): Archivo del doctor Juan María Gutiérrez. Epistolario. Buenos Aires, Biblioteca del Congreso de la Nación, tomo i.

Núñez, E. (2003): "Proceso y teoría de la traducción literaria». En Scholz, L. (sel.): El reverso del tapiz. Antología de textos teóricos latinoamericanos sobre la traducción literaria. Budapest, Eotvós József Kónyvkiadó, págs. 148-156.

Pagés, G.H. (1961): "Virgilio en las Letras Argentinas. De Lavardén a Juan Cruz Varela (conclusión)". Boletín de la Academia Argentina de Letras, xxvi, 1000, págs. 217-310.

Salas Salgado, F. (2012): «Eneida de Virgilio, en la traducción de Tomás de Iriarte (1787)». Alicante, Biblioteca Virtual Miguel de Cervantes (en línea: <http://www. cervantesvirtual.com> [consulta: 23 de febrero de 2017]).

Saldias, A. (1888): "Don Juan Cruz Varela». En La Eneida en la República Argentina. Traducción de los señores Dr. D. Vélez Sársfield y J.C. Varela. Publicada bajo los auspicios de las familias de ambos traductores, y con una reseña sobre ellos por Domingo F. Sarmiento y Adolfo Saldías. Buenos Aires, Félix Lajouane, págs. 297-338.

Schleiermacher, F. (1996): "Sobre los diferentes modos de traducir». Traducción de Hans Christian Hagedorn. En López García, D. (ed.): Teorías de la traducción: antología de textos. Cuenca, Universidad de Castilla-La Mancha, págs. 129-157.

Steiner, G. (2001): “¿Qué es literatura comparada?». En Steiner, G.: Pasión intacta. Ensayos 1978-1995. Madrid, Siruela, págs. 121-145.

Varela, J.C. (1872): "Carta inédita de don Juan C. Varela al Sr. don Bernardino Rivadavia sobre la manera de traducir los poetas latinos y especialmente a Virgilio". Revista del Río de la Plata, 11, tomo iii, págs. 403-418. 
Vega Cernuda, M.Á. (1996-1997): "Apuntes socioculturales de historia de la traducción: del Renacimiento a nuestros días”. Hieronymus Complutensis, 4-5, págs. 71-85.

Weinberg, F. (1977): El Salón Literario de 1837. Con escritos de M. Sastre - J.B. Alberdi -J.M. Gutiérrez - E. Echeverría. Buenos Aires, Hachette. 